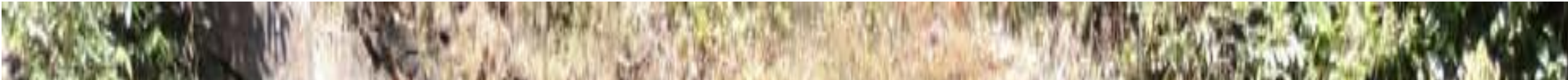
meder. $x+y=$ $03 \times 4 \times 219$ (x) 1925

$2031 \%$

$67(-1) \times$

W. Why



tion $x^{2}$ of

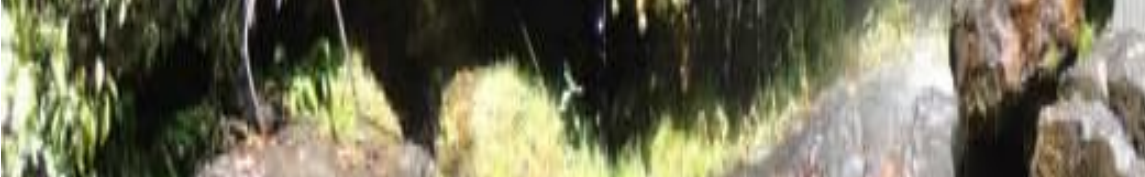
$4 \times 2 x^{k}=0$ $2+2 \sqrt{2}$

$3 \times 1 \times$ an ro

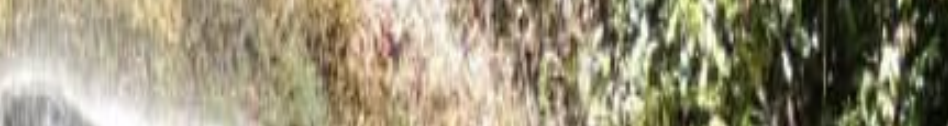
a.


(and

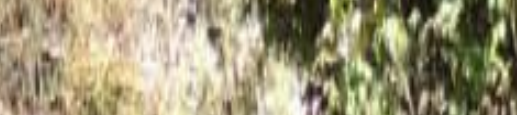


(3)



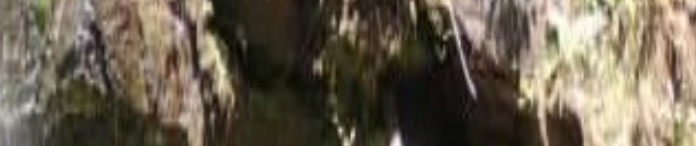

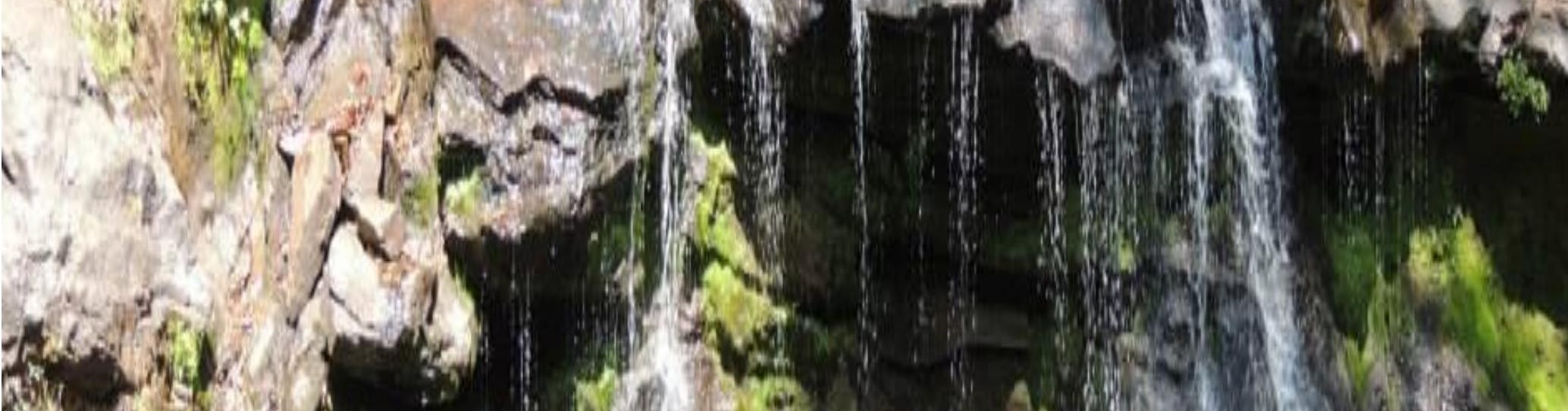

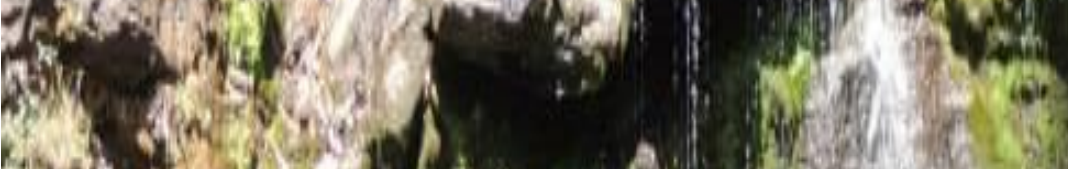

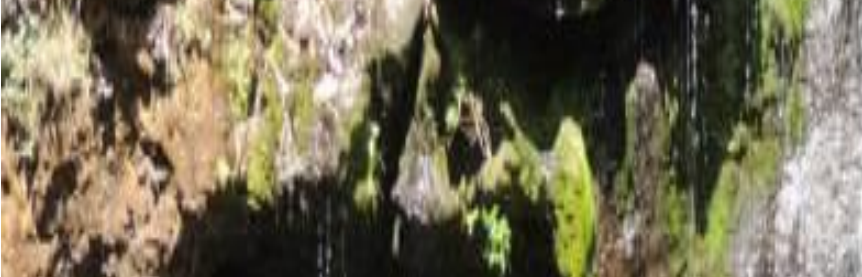

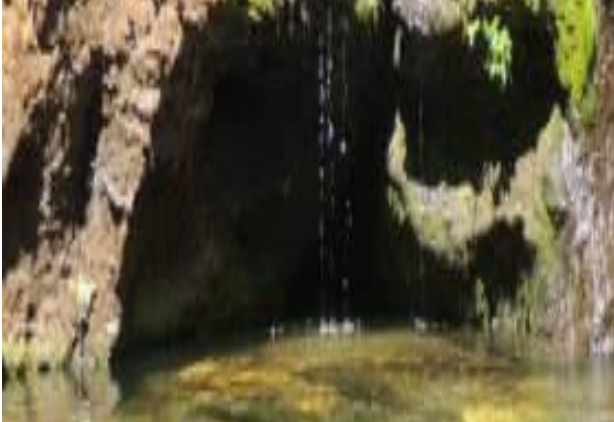

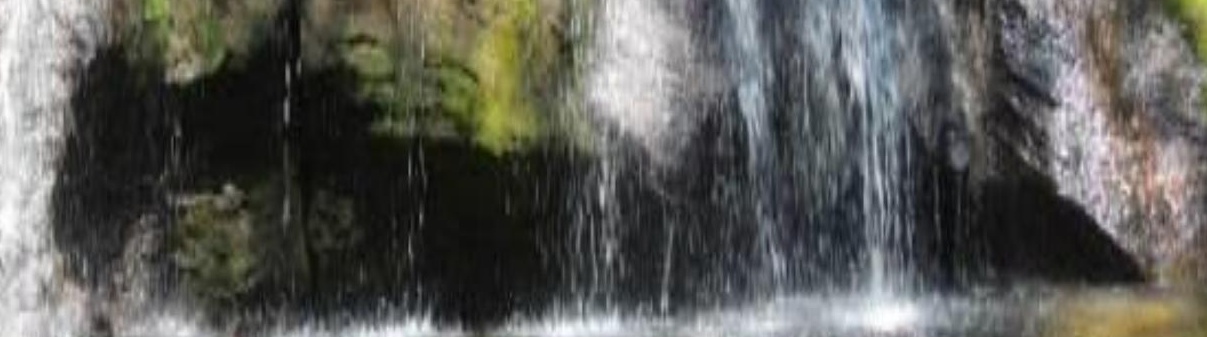

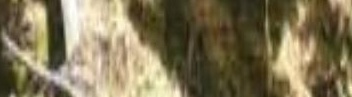
(5)

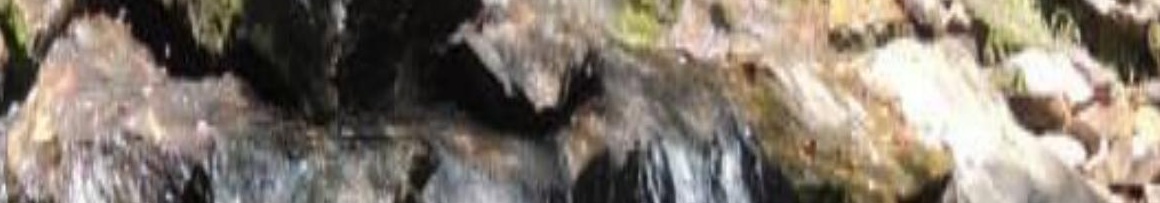

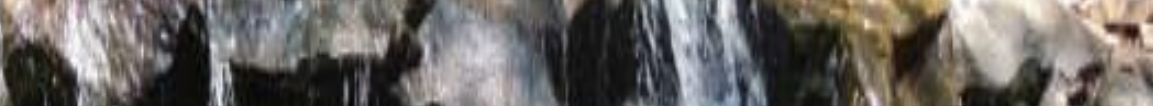

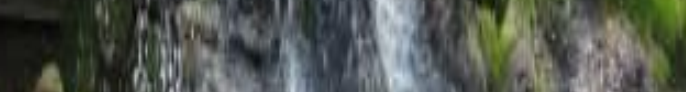




\section{Turismo, patrimônio natural e a relação sociedade-}

\section{natureza}

Tourism, natural heritage and the society-nature relationship

Vitor João Ramos Alves ${ }^{1}$

\footnotetext{
${ }^{1}$ Mestre em Turismo pelo Centro de Excelência em Turismo da Universidade de Brasília - CET/UnB. Graduado em Turismo pelo Instituto de Educação Superior de Brasília - IESB. Experiência profissional na área de Turismo e Gestão. E-mail: vitorjoaoramosalves@gmail.com. Link de acesso ao Currículo Lattes: http://lattes.cnpq.br/1003037867498422
} 


\section{Resumo}

O turismo, concebido pelo sistema capitalista como uma mercadoria a ser consumida pelos turistas, ao associar-se ao patrimônio natural é visto ideologicamente como uma forma de promover a preservação ambiental. Assim, esse trabalho propõe a análise da relação sociedadenatureza e turismo direcionado à preservação do patrimônio natural, a partir de uma pesquisa qualitativa, exploratória e interpretativa, de referências bibliográficas que abarcamos conceitos de turismo e patrimônio natural e a relação sociedade-natureza. Conferiu-se, assim, a necessidade da mudança de posicionamento e postura do turista durante a prática do turismo, de forma ativa, interativa e relevante, a fim de promover o "religar-se" aos valores simples e profundos do Homem, promovendo-o como parte integrante da natureza.

Palavras-chave: Turismo. Patrimônio natural. Relação sociedade-natureza. Ética do cuidado.

\section{Abstract}

The tourism, conceived by the current capitalist system as a commodity to be consumed by tourists, by associating with natural heritage is ideologically seen as a way to promote environmental preservation. This work proposes the analysis of the relationship between society and nature and tourism directed to the preservation of natural heritage, based on a qualitative, exploratory and interpretative research, bibliographical references that cover the concepts of tourism and natural heritage and the relationship between society and nature. The need to change the position and posture of the tourist during the practice of tourism in an active, interactive and relevant manner was thus reinforced in order to promote the "re-linking" with the simple and profound values of Man, promoting him as Integral part of nature.

Keywords: Tourism. Natural heritage. Relationship between society and nature. Ethics of care.

\section{INTRODUÇÃO}

A vida na Terra se iniciou por volta de 3,5 bilhões de anos por seres pouco complexos e microscópicos, conforme abordagens feitas por Fritjof Capra (2006, p. 174). Plantas e animais emergiram do microcosmo há menos de um bilhão de anos e mais de $99 \%$ de todas as linhagens de espécies que existiram no planeta foram extintas ou deram origem a novas linhagens, segundo a história evolutiva.

Edgar Morin (2005, p. 52) acrescenta para essa reflexão que a vida emerge no planeta como emanação e criação da Terra, "se espalha nos mares, alastra-se nos solos que se formam e se cobrem de árvores e plantas, voa nos ares com os insetos e as aves". Obedecendo a segunda lei da termodinâmica, os ecossistemas evoluem por desorganizações e reorganizações: "nossas eras se sucedem através de uma dialética de inovações, acidentes, catástrofes", estabelecendo nesse movimento evolutivo "uma extraordinária cooperação" entre os seres. A vida, portanto, nascida no Planeta, é solidária. Para o autor, "toda vida animal tem necessidade de bactérias, plantas, outros animais" (MORIN, 2005, p. 53), sendo assim, há uma "solidariedade ecológica", onde nenhum ser, até mesmo o Homem, pode libertar-se da biosfera.

No surgimento do século XIX, por meio da revolução industrial, ocorreram grandes mudanças nas relações do homem com a natureza. Tais mudanças, oriundas do isolamento do 
indivíduo, separando-o da sociedade e de seu ambiente natural, continuam a promover, até os dias atuais, um desenvolvimento social-econômico pautado na violência, na destruição, na exploração e na alienação do homem, direcionando-o para a formação de uma sociedade de risco. Esta nova sociedade, cercada de autoameaças em potencial, promove a mercadorização das coisas e a desvalorização da coletividade, dissolve a solidariedade e estimula o individualismo e o egoísmo em seu meio.

A natureza, subjugada e explorada por essas mudanças foi transformada em produto predeterminado e fabricado, tornando-a frágil, o que aumenta a possibilidade de riscos ecológicos, químicos, nucleares e genéticos, fruto do intenso processo industrial típico da sociedade capitalista. O meio ambiente natural é visto isoladamente, como se o ser humano não o integrasse, e sem o questionamento a respeito do ambiente social e cultural que o permeiam. Tal posicionamento é confirmado pelas abordagens feitas por autores como David Harvey (2004) e Ulrich Beck (2010), ao afirmarem que o processo de mercantilização vigente no sistema capitalista pode emergir pelas relações humanas, por diferentes modalidades de comportamento [competitivo, adaptativo ou colaborativo].

O turismo, também influenciado por esse direcionamento, é absorvido pelo desenvolvimento técnico-econômico, que o transforma em um fenômeno tecnológico-industrial, que resulta na sua comercialização global, como um produto.

A partir desse contexto inicial, o presente trabalho busca promover uma reflexão sobre o conceito epistemológico de turismo relacionado com a proteção do patrimônio natural, especificamente na relação sociedade-natureza.

A pesquisa que o embasa permitiu a observação de desdobramentos relativos à postura do turista e suas responsabilidades na prática turística, postura e responsabilidades estas, identificadasna teorização de KarelKosik $(1976$, p. 9), que posiciona o sujeito como um ser que age, de forma objetiva e prática, na sociedade, posicionando-o como construtor de suas escolhas e por suas relações em sociedade, capaz de adotar uma postura responsável perante à natureza".

\section{A RELAÇÃO HOMEM E NATUREZA}

A partir do século XIX, com a "idade de ferro planetária" (Morin e Kern, 2005), a ampliação do desenvolvimento tecnológico e industrial dá-se associada às consequências do imperialismo e do colonialismo explorador massificado, de modo a fortalecer a ruptura do Homem com a natureza. Conforme as teorizações de Ulrich Beck (2010, p. 9), nesse período a natureza passou a ser "subjugada e explorada" e assim, transformada de "fenômeno pré-determinado" em um "fenômeno 
fabricado", a fim de ser absorvida pelo sistema industrial e tornar-se indispensável para o modo de vida industrializado, não importando os riscos consequentes.

Muitas florestas e áreas virgens foram destruídas para fins comerciais nesse período, o que originou a preocupação crescente com a proteção da vida selvagem, de forma a demonstrar que a onda de destruição do mundo natural ameaça a própria existência do Homem sobre a terra. Em sua obra "O Mito Moderno da Natureza Intocada", Antônio Carlos Sant'ana Diegues (2000) refere-se a duas visões de conservação do mundo natural: a visão Conservacionista e a visão Preservacionista, sintetizadas pelas propostas de Gifford Pinchot e John Muir.

A visão Conservacionista, criada por Gifford Pinchot, originou o movimento de conservação dos recursos, apregoando o seu uso racional, por meio da transformação da natureza em mercadoria. Acreditava-se, segundo Diegues (2000, p. 29), que a conservação deveria basear-se em três princípios: "o uso dos recursos naturais pela geração presente; a prevenção de desperdício; e o uso dos recursos naturais para benefício da maioria dos cidadãos". Essas idéias foram precursoras do conceito hoje denominado de "desenvolvimento sustentável".

Já a visão oposta ao Conservacionismo, criada por John Muir como Preservacionista, é descrita como "a reverência à natureza no sentido de apreciação estética e espiritual da vida selvagem" (DIEGUES, 2000, p. 30) e tem como premissa a proteção da natureza contra o desenvolvimento moderno, industrial e urbano. Nessa perspectiva, qualquer intervenção humana na natureza era tida como intrinsecamente negativa.

As teorias sociais do século XIX e as mudanças ocorridas no século XX transformaram a natureza em algo predeterminado, subjugado, a ser explorado e transformado pelo Homem em um produto de consumo, sem levar em consideração a questão da destruição, mas sim a manutenção da dinâmica econômica, política e social do indivíduo. Com isso, o Homem perde sua identidade individual e passa a seguir os padrões comportamentais impostos pelo sistema produtivo.

Milton Santos (2007, p. 51), em suas análises, esclarece que o sistema de produção industrializado, com foco não mais no Homem, senão no mercado, gera "fenômenos históricos condicionados pelos seus interesses específicos", de modo a capturar o Homem nas armadilhas denominadas "bens de consumo". O autor, ao se apropriar do conceito trabalhado por Navarro Britto (SANTOS, 2007, p. 52 apud BRITTO, 1977, p. 344) conceitua a alienação como "o processo de fragmentação do conhecimento e, consequentemente, distorção da realidade humana", apresentando em seguida sua própria definição como sendo "consequência da contraposição do Homem, de um lado, e da economia, da política, da técnica, da cultura etc., de outro lado".

Nesse panorama social, o sentido da vida muda de forma, partindo dos valores éticos e comportamentais para os valores de posse e acúmulo. Os produtos ganham sentido na vida do 
Homem e incentivam-no ao acúmulo dos bens materiais, não para sua sobrevivência, mas para a satisfação do prazer criado e incentivado pelo sistema industrial. 0 trabalho perde o seu significado inicial, o da condição humana, e passa a escravizar o Homem, conforme se dá o desenvolvimento econômico e social. Assim, a transformação da natureza em produto a ser consumido pelo Homem, gera novos ambientes, em rápida escala produtiva, os quais podem emergir em "diferentes modalidades de comportamentos humanos competitivos, adaptativos ou colaborativos", segundo Harvey (2004, p. 276).

Maria Adélia Aparecida de Souza (2009, p. 25) cita em seu artigo intitulado "Meio ambiente e desenvolvimento sustentável - as metáforas do capitalismo" que, nos dias atuais, o conceito de natureza e meio ambiente, além das questões relacionadas com o desenvolvimento e a sustentabilidade, ainda não são discutidas suficientemente do ponto de vista epistemológico e metodológico (teórico e conceitual). O que ocorre são processos geográficos, biológicos e geológicos interagentes que podem e devem ser cientificamente estudados, mas que ainda estão sendo tratados como metáforas, discursos políticos e não como temas científicos.

A questão ambiental tem-se confundido epistemologicamente, misturando em suas abordagens a história da natureza (natureza naturata) com a história do mundo (segunda natureza). A sustentabilidade hoje é interpretada como um discurso político poderoso e falacioso (SOUZA, 2009, p.23), de forma semelhante ao conceito de desenvolvimento, do qual os países pobres acreditam se beneficiar, mas que na verdade, tem como prioridade a preocupação com o mercado e o capital, não com a humanidade, ou seja, a vida no planeta.

Edgar Morin (2005, p. 82) retrata que, atualmente, se vê "a tecnicização generalizada, a industrialização generalizada, a urbanização generalizada, com seus efeitos ambivalentes, sem que ainda se saiba quais irão prevalecer", o que deixa o Homem em uma posição incerta, sem saber como mudar a situação, como dialogar com tais questões e como corrigir as falhas ou combater os riscos gerados, principalmente em relação à natureza, tendendo a adotar postura passiva, deixando o controle na mão do sistema produtivo.

Ao buscar compreender as relações sociais na natureza, Costa et al. (2015) apresentam que são várias as atitudes dos Homens face à natureza, resultantes de diversas concepções de mundo projetadas sobre ela, dentre as quais as de "selvagem, sublime, pura, divina, objeto de conhecimento, útil, recurso, etc." (COSTA et al., 2015, p.2). Desta forma, a natureza presta-se a atender aos apelos do imaginário do indivíduo, tomando-a como estímulo para a prática das atividades cotidianas. Tais, estímulos, quando relacionados ao turismo, alimentam os mitos dos ecoturistas, as preocupações dos ecologistas e dos ambientalistas, as fantasias dos que idealizam a natureza como sagrada, além de atender aos interesses dos que a utilizam como uma mercadoria. Os 
estímulos gerados pelo turismo são: "os recursos naturais - para diversas práticas desportivas; a contemplação e a naturofilia ${ }^{2}$ - enquanto disposição afetiva contemporânea em relação à natureza -" (COSTA et al., 2015, p.3).

Embora o entendimento sobre o natural tenha se ampliado, ainda permanece um posicionamento alheio à intervenção social, como o padronizado pelo sistema capitalista. O capital promove uma relação mercadológica com tudo e com todos os inseridos em seus processos e, da mesma forma, aplica um "valor de troca" aos homens e à natureza. Logo, essa relação deixa de ser "interação" e passa a ser uma "alienação". Essa posição alienada do indivíduo direciona o Homem a uma "sociedade de risco", como tratado por Ulrich Beck (2010) em seu trabalho "Sociedade de risco: Rumo a uma outra modernidade", que incentiva, cada vez mais, o Homem ao acúmulo e ao consumo de bens supérfluos e descartáveis, promovendo o tratamento superficial das questões relacionadas ao ambiente natural e à natureza.

\section{O VALOR SIMBÓLICO DA NATUREZA E SUA PATRIMONIALIZAÇÃO}

A contínua exploração do ambiente natural pelo Homem, originada no modo de produção capitalista pelo domínio das atividades agrícolas, e posteriormente, pela evolução das técnicas industriais, distanciou cada vez mais a vida cotidiana do Homem do meio ambiente. A natureza passou assim a ser vista como fornecedora de matéria-prima e transformada em recurso natural. A partir de então, o Homem, considerado "o rei da criação" por Diegues (2000, p. 23), iniciou o processo de desvalorização do "mundo natural", tornando-se alienado e dominado pelo sistema de produção, o que promoveu a valorização estética da natureza, ou como denomina Diegues (2000, p. 53), o "simbolismo estético".

A distância que separa a sociedade da natureza faz com que os homens, alienados, não visualizem os fenômenos sociais, políticos ou econômicos existentes nessa relação, passando a ver o ambiente natural apenas como uma imagem romantizada, um mundo natural intocado e intocável. Toma-se então, uma atitude de contemplação da natureza selvagem, tornando-a "um lugar de reflexão e de isolamento espiritual", conforme tratado por Diegues (2000, p.24).

O símbolo de "paraíso perdido" remete o Homem urbanizado à idéia de uma beleza primitiva, da apreciação de uma natureza anterior à intervenção humana, da apreciação do belo, do harmonioso, da paz interior proveniente da admiração da paisagem intocada (DIEGUES, 2000, p. 59).

Esse aspecto simbólico da natureza, transformada em arquétipo de um paraíso perdido da

\footnotetext{
${ }^{2}$ Naturofilia, segundo Maria Geralda Almeida, é um termo usado por Roger Béteille na obra "Le tourism vert" do ano de 2000, que expressa a "disposição afetiva, contemporânea, em relação à natureza, sobretudo instigada pelas práticas do turismo que, paradoxalmente, é produtor e consumidor do ambiente" (ALMEIDA, 2008, p. 78).
} 
humanidade, promoveu o avanço do movimento de patrimonialização do espaço natural. O patrimônio [identificado como o reconhecimento de um espaço delimitado e legalmente protegido, inclui tanto edificações e obras (patrimônio histórico cultural) como locais de interesse paisagístico e ecológico (patrimônio natural)] é relacionado conforme os parâmetros estabelecidos pela Organização das Nações Unidas para a Educação, a Ciência e a Cultura - UNESCO -, desde 1948, como:

[...] monumentos históricos, conjuntos urbanos, locais sagrados, obras-de-arte, parques naturais, paisagens modificadas pelo Homem, ecossistemas e diversidade biológica, tesouros subaquáticos, objetos pré-históricos, peças arquitetônicas e tradições orais e imateriais da cultura popular. (BO, 2003, p.17)

A natureza, recebendo o tratamento de "Patrimônio Natural" pela UNESCO, desde 1970, por meio do processo de tombamento, devido seu valor simbólico e de importância preservacionista e histórica para o ambiente natural e o Homem, passou a ser entendida como parte integrante da sociedade, ligada às práticas sociais e à memória cultural da coletividade, conforme as abordagens de Simone Scifoni (2006) em sua tese de Doutorado "A construção do patrimônio natural".

Segundo a autora, o patrimônio natural surge como um produto relacionado à cultura e é possível perceber duas direções no sentido de sua construção teórica. A primeira, no plano mundial, firmando-se como expressão de grandiosidade e beleza, com valor afetivo, e que, por sua vez, advém de um sentido de monumentalidade como preocupação estética. A segunda pressupõe a intocabilidade, ou seja, os grandes testemunhos da natureza monumental e espetacular que foram poupados da intervenção humana (SCIFONI, 2006, p. 27).

Vale também destacar a abordagem trazida por Costa et al. $(2015$, p.14) afirmando que "a natureza é revelada como ponto de interpretações, atrações, representações e transcendências" e que sua patrimonialização supõe a emergência da cultura do estético, que a alinha à natureza social. Tal cultura traduz-se em "consumo visual e representa o empoderamento (às avessas) massivo da e na natureza natural, cuja consciência ou imaginários são reproduzidos no contexto do discurso de fuga das novas angustias ou tormentos urbanos" (COSTA et al.,2015, p. 3).

Para maior visibilidade sobre o que é considerado patrimônio natural, apontam-se os itens relacionados no artigo segundo da Convenção para a Proteção do Patrimônio Mundial, Cultural e Natural ${ }^{3}$, de 16 de novembro de 1972, conforme a seguir:

\footnotetext{
${ }^{3}$ A Convenção para a Proteção do Patrimônio Mundial, Cultural e Natural, também conhecida como Recomendação de Paris, é um compromisso internacional elaborado pela UNESCO e apresentada na Conferência Geral da Organização das Nações Unidas para a Educação, Ciência e Cultura, realizada em 17 de outubro a 21 de novembro, em Paris, no ano de 1972.
} 
Para fins da presente Convenção serão considerados como patrimônio natural:

- os monumentos naturais constituídos por formações físicas e biológicas ou por grupos de tais formações com valor universal excepcional do ponto de vista estético ou científico;

- as formações geológicas e fisiográficas e as zonas estritamente delimitadas que constituem habitat de espécies animais e vegetais ameaçadas, com valor universal excepcional do ponto de vista da ciência ou da conservação; e

- os locais de interesse naturais ou zonas naturais estritamente delimitadas, com valor universal excepcional do ponto de vista da ciência, conservação ou beleza natural (CONVENCIÓN, 2016).

O termo Monumento Natural foi estabelecido no Brasil, pela primeira vez, na Constituição Federal de 1937, promovendo um avanço nas análises a respeito do assunto, conforme apresentado no artigo 134, a seguir:

Artigo 134: os monumentos históricos, artísticos e naturais, assim como as paisagens ou os locais particularmente dotados pela natureza, gozam de proteção e dos cuidados especiais da nação, dos estados e municípios. Os atentados contra eles cometidos serão equiparados aos cometidos contra o patrimônio nacional (BRASIL, 2016a).

Também no ano de 1937, pôde-se ter como referência a primeira legislação federal específica, o Decreto-Lei № 25, de 30 de novembro de 1937, que organiza a proteção do patrimônio histórico e artístico nacional, que em seu artigo primeiro, parágrafo segundo, identifica os monumentos naturais como sujeitos a tombamento, "bem como os sítios e paisagens que importem conservar e proteger, pela feição notável com que tenham sido dotados pela natureza ou agenciados pela indústria humana" (BRASIL, 2016b).

No Brasil, encontram-se como "Patrimônio Natural Mundial" as formações geológicas e regiões que constituem habitat de espécies de animais e vegetais ameaçadas de extinção, com valor científico ou de conservação, como o Parque Nacional da Chapada dos Veadeiros e o Parque Nacional das Emas, no Estado de Goiás, ambos criados no ano de 1961 e incluídos na Lista da UNESCO como patrimônio natural em 2001.

Nesse contexto de ressignificação de lugares, tendo como fator propulsor o empoderamento da natureza natural, merece destaque o processo de votação que vem sendo realizado pela Câmara dos Deputados e pelo Senado Federal para a aprovação de uma Proposta de Emenda à Constituição, a PEC 504/2010, que altera o parágrafo 40 do artigo 225 da Constituição Federal, com o fim de incluir o Cerrado brasileiro e a Caatinga entre os biomas considerados patrimônio nacional, promovendo a regulamentação do uso desses biomas, dentro de condições que assegurem a preservação do meio ambiente e a melhoria da qualidade de vida da população (BRASIL, 2016c). 


\section{A RELAÇÃO SOCIEDADE-NATUREZA PROMOVIDA PELO TURISMO}

Sendo o turismo uma prática transdisciplinar, "que nasce no espírito do filósofo e na luta do sujeito pela liberdade" segundo Moesch (2004, p. 399), identificou-se, na complexidade existente entre a relação do turismo e o patrimônio natural junto à relação sociedade-natureza, o atual posicionamento de transformação da natureza em algo explorado e transformado em produto a ser consumido, como observado nos embasamentos de Everaldo Costa (2010), Milton Santos (2009), Edgar Morin (2005) e Diegues (2000). Tal posicionamento não leva em consideração as questões práticas da preservação ou proteção, que são identificadas por Maria Adélia Souza (2009) como um discurso político falacioso nos dias de hoje, mas sim, a questão da manutenção da dinâmica econômica e política do capital. Com isso, o Homem perde sua identidade individual e se permite seguir padrões comportamentais impostos pelo sistema produtivo.

Contrapondo tal posicionamento, conforme os embasamentos de Mészáros (2009, p. 20), a modificação do modo de pensar a respeito do "domínio do Homem sobre a natureza", tem por consequência uma "mudança na forma de produção e domínio prático da natureza pelo Homem", conforme o trecho em destaque retirado das argumentações de Marx, no Discurso do Método:

\footnotetext{
É possível [aplicando o método que introduziu na filosofia] atingir conhecimentos muito úteis à vida e chegar a uma filosofia prática que substituirá aquela filosofia especulativa aprendida nas escolas [modelo cartesiano]. Através dessa filosofia prática, que nos leve a conhecer a força e os efeitos do fogo, da água, do ar, dos astros e de todos os demais corpos que nos cercam, de maneira tão clara quanto conhecemos os diversos ofícios de nossos artesãos, nós poderíamos utilizá-los com a mesma eficiência e para todos os fins a que são adequados e assim nos tornar senhores e possuidores da natureza e contribuir para aperfeiçoar a vida humana (MÉSZÁROS, 2009, p. 20).
}

Mészáros (2009, p.20) ainda relaciona sua análise com a forma como a humanidade poderia alcançar o domínio consciente das condições materiais e humanas da reprodução social, ou melhor, "o domínio dos homens sobre si mesmos", suas condições sociais de existência e o intercambio humano, que, conforme o autor, "inegavelmente afeta, frustra e, em última análise, chega a anular também a realização da tarefa mais limitada de domínio do Homem sobre a natureza", o que equivale apenas a obedecer cegamente aos imperativos do valor de troca.

O autor também apresenta que as práticas produtivas vigentes, identificadas como dominantes, estão ligadas indissoluvelmente às práticas das ciências naturais sob o domínio da lógica do capital, dos interesses do valor de troca e da ideologia que permeia o "avanço social" em suas propostas. Tais pontos de vista têm como base de interesse, relacionados diretamente à economia política, conforme os embasamentos do autor, a expansão produtiva por meio da ciência e da conformidade ideológica desse avanço social (MÉSZÁROS, 2009, p. 25). 
Uma das principais características que define o modo de produção aqui analisado, o qual autentica diretamente o plano da consciência social, é a tendência geral ao "formalismo abstrato do horizonte global" imposta pela prática, conforme definido por Mészáros (2009, p. 27-28). Para o autor, os interesses ideológicos que dão base a essa tendência universalista estão direcionados (i) à transformação abstrata / redutora das relações humanas hierarquizadas e protegidas pelo sistema produtivo e distributivo capitalista; (ii) à articulação consistente e difusora de "igualdades" ou "equiparações" requeridas para o funcionamento prático do mecanismo produtivo e distributivo do capital; (iii) à eliminação da dimensão histórica da vida socioeconômica do campo de visão, graças a metamorfoses das categorias resultantes das práticas abstratas/redutoras.

O formalismo, também observado em algumas práticas turísticas, tem como função uma efetiva mudança conceitual, que visa transferir os problemas e as contradições da vida real, transpostos do plano social para a esfera legislativa da razão, para formas universais válidas ou conflitos opostos de maneira formalista (MÉSZÁROS, 2009, p. 28).

Por meio dessa interpretação, pode-se concluir que o "turismo", identificado nesse trabalho como "incentivador" à preservação do patrimônio natural, surge como uma "mudança conceitual", a fim de atender uma ideologia pautada na beneficência da conservação, mas com uma intrínseca personificação do capital, que ainda atende interesses apenas mercadológicos na sociedade.

\section{A ÉTICA BASEADA NA NATUREZA}

Tendo como base as obras pesquisadas, observou-se que a relação sociedade-natureza tem como princípio básico a ética, ou seja, o cuidado e a construção da morada do ser humano. Leonardo Boff $(2007$, p. 36) ainda esclarece que a natureza é um "conjunto articulado de todas as energias cósmicas em processo de materialização ou desmaterialização" na qual o ser humano possui um lugar singular. Merece destaque, para facilitar a análise, o trecho a seguir:

\footnotetext{
O ser humano possui nela [natureza] um lugar singular. Ele desempenha uma dupla função. Por um lado, está dentro, é parte da natureza, inserido no imenso processo de evolução natural e cibiôntica. Por outro, está de frente, é um vis-à-vis à natureza. Por sua consciência e por seu saber técnico, intervém nela, fazendo-se seu plasmador. Nem por isso deixa de ser parte da biosfera e geologicamente um objeto bem concreto. $\mathrm{O}$ ser humano é sempre parte da natureza e interventor da natureza. A relação ser humano-natureza é dialética, quer dizer, ambos se encontram indissoluvelmente intrincados um no outro, de tal forma que o destino de um se transforma no destino do outro (BOFF, 2007, p. 36-37).
}

Nesse contexto, o ser humano se encontra enraizado na natureza e se posiciona como parte integrante da mesma, como um "ser-no-mundo", que interage com outros seres, por meio da 
convivência, com capacidade de exteriorizar o movimento do cuidado, da responsabilidade por sua vida e pela vida dos demais, além de construir o seu próprio futuro.

Ainda com base em Leonardo Boff (2007, p. 39), pode-se registrar que há atualmente, no campo da ética e da moral, seis formas principais de argumentação a respeito da criação de valores, válidos para todos, para a construção de uma ética planetária. São elas: o utilitarismo social; as éticas do discurso comunicativo e da justiça; a ética baseada na natureza; a ética enraizada nas tradições religiosas da humanidade; a ética fundada no pobre e no excluído; e por fim, a ética fundada na dignidade da Terra.

Tendo como foco desta pesquisa a relação sociedade-natureza e o turismo, juntamente com o patrimônio natural, é válido explorar as análises de Leonardo Boff a respeito da ética baseada na proteção da natureza. Para o autor (2007, p. 51-55), o clássico formulador da argumentação ética pela lei natural é Tomas de Aquino, que teve como base teórica os embasamentos de Aristóteles. A moral católica, especificamente retratada nos documentos do magistério pontifício, direciona os indivíduos por meio dessa tendência, com base na conviç̧ão de que a autonomia dos sujeitos deve tomar em conta aquilo que se adapte, convém e se coordena com os condicionamentos objetivos da natureza humana. A partir dessa natureza humana, pode-se distinguir o ser humano dos animais, das plantas e dos demais seres vivos, definindo-o como uma espécie que possui um comportamento singular, propriamente humano, caracterizado pela razão, pela fala, pela liberdade, pela responsabilidade, pela criatividade, pelo afeto, pelo cuidado e por sua vez, pela interação com o outro, com o mundo e sua totalidade.

É importante ressaltar que essa capacidade única do ser humano se estabelece enquanto conceito operacional frente a tudo que possa ser considerado ameaçador e perigoso, objetivando, sobretudo, a autopreservação e a sobrevivência humana, e também, a sobrevivência do mundo animal ou ambiental. Desse modo, o "cuidado", considerado nesta pesquisa como uma ação de cuidar, situa-se enquanto comportamento, ação explícita ou implícita, pelo pensar e agir humanos. É tanto a expressão de um sentimento afetivo como de uma reflexão racional, ambas entendidas como determinantes da capacidade e da potencialidade humana.

O "cuidado" é, portanto, uma atividade ou atitude que envolve mecanismos psicológicos afetivo, racional, comportamental - que promovem concordâncias e contradições sociais, as quais permeiam a esfera da identidade, do ser como indivíduo social, e que se expressa enquanto configurações sociais nas dimensões qualitativas do campo de abrangência da conexão humana e da empatia.

Esse processo de socialização humana começa, conforme os estudos de Castoriadis (1999), com o nascimento e termina com a morte do indivíduo, e o autor ainda acrescenta: 
Ele [o processo] faz do ser humano uma entidade que fala, tem uma unidade social, um estado social, é habitado e determinado por regras, valores, fins e possui mecanismos de motivação que são sempre mais ou menos adequados à manutenção da sociedade existente (CASTORIADIS in PENA-VEGA; ALMEIDA [Org.], 1999, p. 43).

A reflexão crítica sobre a prática atualmente realizada no turismo se torna uma exigência na relação sociedade-natureza, enquanto Teoria e Prática, sem a qual a teoria se transformaria em um discurso falacioso e a prática, um atavismo. Esse movimento dinâmico, dialético, entre o "fazer" e o "pensar criticamente sobre o fazer" é muito bem abordado por Paulo Freire (1996) em sua obra "Pedagogia da Autonomia".

Conforme os embasamentos do autor:

É pensando criticamente a prática de hoje ou de ontem que se pode melhorar a próxima prática. $O$ próprio discurso teórico, necessário à reflexão crítica, tem de ser tal modo concreto que quase se confunda com a prática. (FREIRE, 1996, p. 3839).

Quanto mais o turista se assume como sujeito que promove mudanças quando em prática na sociedade, mais percebe as razões de ser tornar capaz de mudar a sua realidade, de promover mudanças, no caso, alterando seu próprio estado de "curiosidade ingênua" para o de "curiosidade epistemológica", segundo as idéias de Paulo Freire (1996, p. 39).

O que importa, na prática turística realizada, não é a repetição mecânica do gesto, sem reflexão ou crítica a respeito, mas a compreensão dos valores dos sentimentos, das emoções, do desejo, da insegurança a ser superada, do medo que, ao ser "educado", vai gerando coragem. Posicionamento este que vai ao encontro das abordagens de Krippendorf (2009).

Ao identificar o "cuidado" como sendo a relação existente entre o ser humano e as questões relativas à ética e à moral, implica-se uma responsabilidade ao sujeito - turista - de construir a ética do cuidado, quando em prática no turismo e na preservação do patrimônio natural. Assim, encontrase nas abordagens de Leonardo Boff (2007, p. 79-86), a proposição raiz para se atingir tal objetivo, por meio do fator identificado inicialmente, ou seja, a capacidade de "sentir", de "ser afetado" e de "afetar" do ser humano.

Segundo o autor (BOFF, 2007, p. 81), a existência jamais é pura existência, é uma "coexistência", sentida e afetada pela ocupação e pela preocupação, pelo cuidado e pela responsabilidade do ser no mundo e com os demais seres. Exige-se, assim, um "sentir" o mundo, os outros, os demais seres, além do próprio "eu" individual, como uma totalidade única e complexa, inserido no mundo, como parte dele e, ao mesmo tempo, que interage com ele. O sentimento, conforme Boff (2007, p. 85), também é uma forma de conhecimento, mas de natureza diversa, a qual se insere na razão, transbordando-a por todos os lados. 
Nesse contexto, ao resgatar a relação sociedade-natureza, o Homem precisa tomar consciência de que é e faz parte integrante da natureza, senti-la como totalidade, cônscio de que suas ações e reações interferem diretamente em si próprio e no meio em que está inserido. Tal tomada de consciência também pode ser interpretada como uma "socialização da natureza", de acordo com as abordagens já citadas de Costa et al. (2015) e Almeida (2008), que propõem, por meio da comunhão entre o indivíduo e a natureza natural, a realização de uma série de operações simbólicas que visem à concretização e à robustez da identidade social, tanto do indivíduo quanto da própria natureza.

Os autores (COSTA et al., 2015, p. 50) questionam em seus apontamentos, se será possível ocorrer uma prática do turismo sem destruir as especificidades ambientais e culturais, hoje consideradas como bens patrimoniais turísticos; e concluem que, no sistema capitalista regido pela lógica da construção destrutiva do patrimônio, há casos reveladores de valorização do lugar, dada a maior participação comunitária na definição das estratégias de desenvolvimento do turismo local, de ações comunitárias em prol do setor e da negociação de parcerias entre os atores públicos, privados e associativos na busca de caminhos que conciliem a preservação do patrimônio natural com a prática do turismo.

A responsabilização advinda da participação comunitária pode ser associada aos embasamentos de Amartya Sen (2010), quando em sua obra "Desenvolvimento como liberdade", o autor associa a liberdade individual com o comprometimento social de todos os envolvidos no processo criador. Os seres humanos competentes (SEN, 2010, p. 359 não podem se furtar da tarefa de avaliar o modo como as coisas são e da responsabilidade de fazer o que precisa ser feito para introdução de melhorias. Essa responsabilidade, diz o autor, "não é tanto uma questão de ter regras exatas sobre como devemos agir, e sim de reconhecer a relevância de nossa condição humana comum para fazer as escolhas que se nos apresentam" (SEN, 2010, p. 360).

Amartya Sen (2010) em sua obra analisa o desenvolvimento como forma de expansão das liberdades reais que as pessoas desfrutam, denominadas pelo autor como liberdades humanas, as quais dependem de outros determinantes, como as disposições sociais e econômicas [liberdade à educação e à saúde] e os direitos civis [liberdade de participar de discussões e averiguações públicas].

Já que o turismo ainda se apresenta, de forma prática, arraigado aos interesses capitalistas, o que promove uma ressignificação do patrimônio natural em atrativo a ser consumido, nada mais justificável do que tentar reverter esse modelo definido pelo capital com o foco no ser humano, ou seja, partindo dele, por meio de investimento no capital humano, não o capital humano destinado ao aumento das possibilidades de produção mercantil, mas sim, no propósito de educar e potencializar 
sua capacidade de fazer escolhas, de agir e promover mudanças que valorizem e aperfeiçoem sua interferência no território e no meio ambiente ao qual pertence.

Surge, assim, a necessidade de sensibilização do próprio turista quando em prática turística. A tomada de consciência, enquanto ação reflexiva - eu comigo mesmo - é uma exigência humana, é um dos caminhos para que seja possível a construção da prática da "curiosidade epistemológica" citada por Paulo Freire, o que promove, assim, a construção de uma ética do cuidado.

Dessa forma, a afirmação de que a socialização da natureza e a construção de uma ética do cuidado são, seguramente, as práticas mais imperativas a serem adotadas nos dias atuais, dado o nível de descuido que paira como uma ameaça ao Homem sobre a Terra. O aprendizado de tais práticas promoverá uma postura de preocupação com o próprio ser humano e com a natureza, o que possibilitará o surgimento do sentimento de responsabilidade, capaz de salvaguardar a Terra como um sistema vivo e complexo, proteger a vida e garantir a convivência em sociedade, por meio da solidariedade, da compreensão, da compaixão e do amor aos seres humanos e por toda criatura viva no planeta.

\section{CONSIDERAÇÕES FINAIS}

No mundo capitalista, regido pela lógica do mercado, o turismo é promovido como um enorme potencial de desenvolvimento econômico e gerador de emprego e renda. Ao mesmo tempo, promove a exploração do ambiente natural e ressignifica-o como atrativo turístico. Assim, o desafio maior para planejadores e empreendedores do turismo, a fim de promovê-lo como fenômeno humano, será o de utilizar a potencialidade e a capacidade de tomada de decisão dos turistas na elaboração de práticas turísticas menos impactantes e que permitam a relação sociedade-natureza mais compassada, respeitando o território, a sociedade e o patrimônio natural. Tal direcionamento pode gerar diretrizes locais e políticas públicas articuladas e mais democráticas, associadas à ética do cuidado e à socialização da natureza, visando a preservação do patrimônio natural.

Esse desafio implica também, na retomada de debates críticos e reflexões participativas sobre novas posturas, éticas e morais, que norteiem a prática do turismo, direcionando-as à educação do sujeito que a pratica. Dessa forma, o turismo deve ser pautado em uma prática emancipatória, que promova mudanças de atitudes e comportamentos e a participação coletiva e altruísta do turista na preservação do patrimônio natural. Exige-se assim a multiplicação das práticas sociais, por meio da criação de espaços de convivência que desencadeiem mudanças estruturais e congruentes, relações de interdependência, adaptação e organização ecossistêmica, integrando a sociedade novamente à natureza. 
Rever o posicionamento e a postura do turista torna-se essencial para a transformação do modo de se fazer turismo, a fim de influenciar e modificar epistemologicamente o turismo enquanto campo do saber e como fenômeno social. O turista precisa também exercer um papel ativo, interativo e relevante no decorrer da prática do turismo no ambiente visitado, de forma a "religarse" aos valores simples e profundos do Homem como parte integrante da natureza. Tais discussões favorecem análises a respeito da prática do turismo como um fenômeno social, e não apenas econômico.

Finaliza-se esse trabalho reforçando a importância da tomada de consciência com relação à preservação do patrimônio natural, citando Leonardo Boff: "para cuidar do planeta precisamos todos passar por uma alfabetização ecológica e rever nossos hábitos de consumo" (BOFF, 2007, p. 134). Importa assim, favorecer discussões e análises a respeito da prática do turismo como fenômeno social e desenvolver uma ética do cuidado.

\section{REFERÊNCIAS}

ALMEIDA, Maria Geralda de. Ambiguidades e contradições no discurso de naturofilia. Desenvolvimento e Meio Ambiente, n. 18, p. 7786, jul./dez. Editora UFPR, 2008.

BECK, Ulrich. Sociedade de risco: rumo a uma outra modernidade. Tradução: Sebastião Nascimento. Editora 34 Ltda. São Paulo, 2010.

BO, João Batista Lanari. Proteção do patrimônio na UNESCO: ações e significados. UNESCO. Brasília, 2003.

BOFF, Leonardo. Ethos Mundial: um consenso mínimo entre os humanos. 2a ed. Editora Sextante. Rio de Janeiro, 2003.

Petrópolis/RJ, 2007.

Saber cuidar: ética do humano - compaixão pela terra. 13a ed. Editora Vozes.

BRASIL. Constituição dos Estados Unidos do Brasil de 1937. Disponível em: <http://www.planalto.gov.br/ccivil_03/Constituicao/Constituicao37.htm>. Acessado em: 20 jan. 2016a.

Decreto-Lei no 25, de 30 de novembro de 1937. Disponível em: <http://www.planalto.gov.br/ccivil_03/decreto-lei/Del0025.htm>. Acessado em: 20 jan. 2016b.

. Lei no 9.608 de 18 de fevereiro de 1998. Presidência da República. Disponível em: <http://www.planalto.gov.br/ccivil_03/LEIS/L9608.htm>. Acessado em: 7 nov. 2015.

PEC 504/2010 - PEC transforma Cerrado e Caatinga em patrimônio nacional. Disponível em: <http://www2.camara.leg.br/ camaranoticias/noticias/MEIO-AMBIENTE/150021-PEC-TRANSFORMAAcessado em: 2 dez. 2015. 
CERRADO-E-CAATINGA-EM-PATRIMONIO-NACIONAL.html>. Acessado em: 26 jan. 2016c.

CAPRA, Fritjof. A teia da vida: uma nova compreensão científica dos sistemas vivos. Tradução: Newton Roberval Eichemberg. Cultrix. São Paulo, 2006.

COSTA, Everaldo Batista da. A dialética da construção destrutiva na consagração do patrimônio mundial. Humanitas: FAPESP. São Paulo, 2010.

Cidades da Patrimonialização Global - simultaneidade totalidade urbana

- totalidade-mundo. Humanitas, FAPESP. São Paulo, 2015.

COSTA, Everaldo Batista da; ALMEIDA, Maria Geralda de; OLIVEIRA, Rafael Fabrício de et RÚBIO, Rúbia de Paula. Realização social da natureza pelo turismo na Chapada dos Veadeiros. Revue francobrésilienne de géographie. №.25. Revista Online, 2015.

DIEGUES, Antonio Carlos Santana. O mito moderno da natureza intocada. 3a ed. Hucitec, Núcleo de Apoio à Pesquisa sobre Populações Humanas e Áreas Úmidas Brasileiras, USP. São Paulo, 2000.

FREIRE, Paulo. Pedagogia da Autonomia: saberes necessários à prática educativa. 41a ed. Paz e Terra. Coleção Leitura. São Paulo, 1996.

HARVEY, David. Espaços de Esperança. Edições Loyola. São Paulo, 2004.

KOSík, Karel. Dialética do Concreto. Tradução de Célia Neves e AldericoToríbio. 2a ed. Editora Paz e Terra S. A. Rio de Janeiro, 1976.

KRIPPENDORF, Jost. Sociologia do Turismo: para uma nova compreensão do lazer e das viagens. Tradução: Contexto Traduções. 3ạ ed. revisada e ampliada. Editora Aleph. São Paulo, 2009.

MÉSZÁROS, István. Estrutura social e formas de consciência: a determinação social do método. Tradução Luciana Pudenzi, Francisco Raul Cornejo, Paulo Cezar Castanheira. Boitempo. São Paulo, 2009.

MOESCH, Marutschka Martini. A produção do saber turístico. 2a ed. Contexto. São Paulo, 2002.

. Epistemologia Social do Turismo. Tese de Doutorado em Relações Públicas, Propaganda e Turismo, da Escola de Comunicação e Arte da Universidade de São Paulo. V. 1 de 2. São Paulo, 2004.

MORIN, Edgar. Introdução ao pensamento complexo. Tradução Eliane Lisboa. 4ạ ed. Sulina. Porto Alegre, 2011.

. Ciência com Consciência. Tradução: Maria D. Alexandre e Maria Alice Sampaio Dória. 5a ed. Bertrand Brasil. Rio de Janeiro, 2001.

. Os sete saberes necessários à educação do futuro. Tradução Carina Eleonora F. da Silva e Jeanne Sawaya. 2ª ed. São Paulo: Cortez; Brasília, DF: UNESCO, 2000.

MORIN, Edgar; KERN, Anne-Brigitte. Terra Pátria. Tradução: Paulo Azevedo Neves da Silva. 5a ed. Sulina. Porto Alegre, 2005. 
PENA-VEGA, Alfredo; ALMEIDA, Elimar Pinho de [Org.]. O pensamento complexo: Edgar Morin e a crise da modernidade. Garamond. Rio de Janeiro, 1999.

SANTOS, Milton. O espaço do cidadão. 7ạ ed. Editora da Universidade de São Paulo. São Paulo, 2007. A natureza do espaço: Técnica e Tempo, Razão e Emoção. 4a ed. Editora da Universidade de São Paulo. São Paulo, 2009.

SANTOS, Milton; SILVEIRA, María Laura. O Brasil: território e sociedade no início do século XXI. 10a ed. Record. Rio de Janeiro, 2001.

SCIFONI, Simone. A construção do Patrimônio Natural. Tese de Doutorado em Geografia pela Faculdade de Filosofia, Letras e Ciências Humanas da Universidade de São Paulo. São Paulo, 2006.

SEN, Amartya. Desenvolvimento como liberdade. Tradução: Laura Teixeira Motta; Revisão técnica: Ricardo Dominelli Mendes. Companhia das Letras. São Paulo, 2010.

SOUZA, Maria Adélia Aparecida de. Meio Ambiente e desenvolvimento sustentável - As metáforas do capitalismo. Cronos, Natal-RN, v.10, no.2, p. 101 -117, jul./dez. 2009. 
